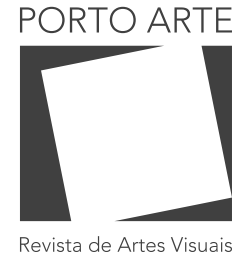

v. 25 n. 43 Jan/jun 2020 e-ISSN: 2179-8001

\section{Warhol e Duchamp: o cotidiano e o design incorporados à arte}

Warhol and Duchamp: the commonplace and the design incorporated into art

\section{Sérgio Luciano da Silva}

ORCID: 0000-0003-4379-339x

Universidade do Estado de Minas Gerais

\section{Resumo}

Este artigo apóia-se nas interpretações do filósofo Arthur Danto sobre as concepções de Andy Warhol e sua obra, procurando compreender como ocorre a apropriação de objetos do design por esse expoente da Pop-Art. Ao lado de Danto, o filósofo Thierry de Duve contribui para a compreensão das influências de Marcel Duchamp e do Dadaísmo, no trabalho de Warhol. O objetivo desta investigação é comprovar como a ação de Warhol promove uma mudança na significação dos objetos utilitários conduzindo-os do universo do design para o artístico. Nossa hipótese é de que a atuação desse artista, assim como a de seu antecessor, Duchamp, produz um desvio ontológico ao "transfigurar" objetos triviais, de uso cotidiano, em obras de arte, sem alterar suas características físicas.

Palavras-chave

Teoria e crítica do design. Filosofia. Arte. Estética.

\section{Abstract}

This paper is based on the interpretations of the philosopher Arthur Danto on the concepts of Andy Warhol and his work, seeking to understand how the appropriation of objects of design occurs by this exponent of Pop-Art. Along with Danto, the philosopher Thierry de Duve contributes to the understanding of the influences of Marcel Duchamp and Dadaism, in Warhol's work. The purpose of this investigation is to demonstrate how Warhol's action promotes a change in the meaning of utilitarian objects, leading them from the universe of design to the artistic. Our hypothesis is that the artist's performance, as well as his predecessor's, Duchamp, produces an ontological detour by "transfiguring" trivial objects, of everyday life, into works of art, without changing their physical features.

Keywords

Theory and critique of design. Philosophy. Art. Aesthetic. 


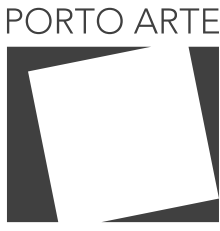

Revista de Artes Visuais

$\vee 25 n .43$

Jan/jun 2020 e-ISSN: 2179-8001

\section{Prolegômenos: uma ontologia do inteligível e outra do sensível}

O título deste artigo inicia-se deliberadamente com uma inversão cronológica ao colocar Andy Warhol, que atua intensamente nos anos de 1960 e 1970, precedendo a Marcel Duchamp, que estabelece um fulcro na arte institucionalizada ainda no final da segunda década do século XX. Subjacente a essa transgressão histórica encontra-se nosso interesse ligado ao design (e de certo modo, também do filósofo e esteta Arthur Danto, por motivos distintos do nosso) em destacar a relevância de Warhol para a contemporaneidade da arte e da cultura, de um modo exclusivo em relação à proposta radical e originária de Duchamp.

Com relação à terminologia, é preciso explicitar o que entendemos por ontologia, dada a complexidade desta área, ao fato de sua significação estar longe de ser consensual entre os pesquisadores, mas principalmente por ela conduzir a abordagem e estabelecer os limites da presente investigação.

A ontologia, como os demais ramos da filosofia, chega à atualidade acumulando diversas variantes de significado, derivadas da trajetória histórica do pensamento ocidental, ao passar pelos estudiosos que vêm se dedicando a essa área em seus temas de trabalho. Assim, considerando-a em seu caráter mais geral, ontologia carrega o sentido de reflexão e busca por compreensão da dimensão mais ampla da realidade, em que cada ente que a compõe (finito ou infinito, material ou imaterial) tem sua existência estabelecida, definida e validada, ou não, dependendo do modo como cada pensador elabora sua teoria. Por exemplo, se entendermos a arte em seu sentido ontológico, ou seja, como um ente que compõe a realidade, na concepção platônica ela é mera imitação, cópia, não existindo enquanto um elemento essencial do real, consequentemente não sendo legitimada como é a ciência na ontologia proposta por esse pensador. Já para outras concepções ontológicas, como a de Aristóteles, primeiro filósofo a questionar Platão nesse âmbito, ou para Arthur Danto na atualidade, a realidade não é cindida em dois mundos: um mundo inteligível, das ideias eternas e transcendentes, onde originam-se o conhecimento, a ciência e a verdade; outro, sensível, em que vivemos e agimos, formado apenas de aparências e imitações.

A oposição de Aristóteles (1987) e Danto (2005) à concepção ontológica platônica do real, oposição essa à qual também nos filiamos, entende a arte e o design, objetos deste artigo, pertencendo legitimamente à realidade, isto é, dois campos com fundamentos ontológicos que os colocam em pé de igualdade com a ciência e não em uma estrutura hierarquizada da realidade e do conhecimento.

Grosso modo, a visão platônica, que privilegia o mundo inteligível, a ciência, a técnica e os valores numéricos quantificáveis de um lado, e a aristotélica, que não nega o mundo sensível e privilegia os elementos qualitativos de outro, avançaram como dois modos de pensar a realidade nas mais diversas variantes conceituais ao longo da história das ideias no Ocidente. Ambas se preservam, nem sempre de modo explícito, ainda hoje em distintas formas de manifestação do conhecimento e da cultura, incluindo posicionamentos dentro da arte e do design. 


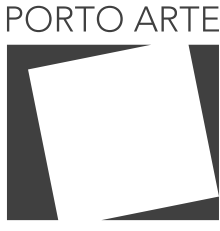

Revista de Artes Visuais

v. 25 ก. 43 Jan/jun 2020 e-ISSN: 2179-8001

Assim, tendo estabelecido de modo abreviado essas duas direções ontológicas, no texto a seguir procuramos identificar como essas construções teóricas antagônicas compõem um quadro dentro do qual se inserem Andy Warhol e Marcel Duchamp e suas obras. Neste sentido, Arthur Danto, principal autor com o qual dialogamos ao longo deste artigo, oferece suporte à nossa investigação, uma vez que ele também usa como pano de fundo esse referencial da disputa do platonismo com seus opositores. Nossa hipótese é de que a ação dos artistas é capaz de produzir um desvio ontológico que conduz e transforma um objeto trivial, de uso cotidiano, fruto do design, em obra de arte. Vejamos como tal operação ocorre.

\section{Warhol: ingênuo ou perspicaz?}

Danto sintetiza sua defesa em favor da relevância do mundo sensível, do cotidiano e por que não dizer, do ordinário, na apropriação que a arte contemporânea faz desses elementos. A seguinte afirmação desse autor, em um ensaio sobre Andy Warhol, apresenta diversos elementos interligados que subsidiam nossa compreensão:

Tinha prometido dar alguma explicação sobre como a exaltação do ordinário ajudou a dar à arte uma consciência de sua natureza filosófica. Os expressionistas abstratos certamente se assumiram como metafísicos na pintura, e acreditaram que a sua arte conectava-se com uma série de sentidos a que tinham acesso pelo inconsciente. Eles usaram a linguagem da filosofia com rebuscamento, e falaram com familiaridade sobre o Self, o noumênico, o Ding an sich. O mundo ordinário, como na grande tradição vinda de Platão, era menosprezado como inferior, como mero, como alheio à realidade com a qual supunham-se em contato. A relação entre arte e realidade não poderia ser constituída nas estruturas que eles tornaram possíveis. Só poderia ser quando se pudesse aceitar um objeto ordinário, i.e., ver que alguma coisa poderia ser arte e ainda se parecer com um objeto ordinário, da mesma forma que os objetos ordinários se parecem entre si. Uma vez que isso foi possível, ficou imediatamente claro que a arte não era o que a teoria dos expressionistas abstratos havia promulgado e não poderia ser filosoficamente concebida enquanto estivesse naquela forma. 0 entendimento filosófico começa quando se percebe que nenhuma propriedade visível distingue a realidade da arte em geral. $E$ isso foi algo que finalmente Warhol demonstrou. (DANTO, 2004, p. 112)

O primeiro ponto significativo para o nosso caminho é a contraposição que Danto faz entre a atitude dos expressionistas abstratos e a atitude de Warhol. Danto identifica os primeiros com a mesma postura advinda de Platão, de crítica ao mundo sensível: 


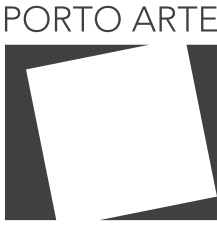

Revista de Artes Visuais

$\vee 25 n .43$ Jan/jun 2020 e-ISSN: 2179-8001

"mundo ordinário", nas palavras de Danto. Subjacente à posição dos expressionistas abstratos é que, se para Platão a arte, enquanto imitação, busca seus objetos no mundo sensível e tal procedimento é condenado por esse filósofo, deve-se afastá-la do mundo sensível, buscando no mundo inteligível a verdadeira realidade. Não sem razão Danto os rotula "metafísicos da pintura".

Ao unir Platão ao Expressionismo Abstrato, contrapondo-os à Pop-Art, na figura de Warhol, Danto, ao mesmo tempo, favorece três elementos em nossa posição:

1- Confirma Warhol como um artista que, conscientemente, ou não, faz parte dos que criticam a posição platônica e a tradição que a segue, tradição essa que concebe a realidade de modo hierarquizado a partir do inteligível, onde o sensível não tem relevância.

2- Concomitante ao primeiro elemento, se o sensível faz parte da realidade, o ordinário passa a ter seu status ontológico reconhecido como relevante para a cultura e o saber.

3- Possibilita a associação dos "objetos ordinários" com os produtos de design.

Analisando a lista anterior, em relação ao primeiro item e à dúvida sobre Warhol estar consciente do que faz, enquanto artista, Danto não acredita na sua ingenuidade, mas cita diversos personagens da cena nova-iorquina das décadas de 1960 e 1970 que pensam assim. Entre eles, o escritor Thom Jones põe nas palavras de um narrador de suas histórias a seguinte afirmação:

Ele [Andy Warhol] - o que ele tinha, era como uma grande antena de rádio. Funcionava em todas as vibrações cósmicas. Ele apenas fazia as coisas, acho que não sabia a metade delas. Ele era um desses idiotas engenhosos, penso. Suas pinturas são muito vagas, Vick. Não consigo fazer uma leitura delas. (JONES, Thom, "The pugilist at rest", 1993, apud DANTO, 2004, p. 99).

A descrição de Jones, contrária à compreensão de Danto, carrega um posição crítica ao substituir a consciência pela inspiração na caracterização de Warhol, comparando-o com "uma grande antena de rádio". Subjacente a tal afirmação encontra-se uma tradicional concepção da arte, enquanto atividade inspirada, que vem, pelo menos, desde Platão. No diálogo Íon', Platão (2011) afirma que o poeta e o rapsodo não se guiam por uma tékhne ou epistéme, mas falam fora de si, possuídos pelo deus, entusiasmados e sem consciência. Não obstante esse entendimento que Jones expressa

\footnotetext{
1- Luís Felipe Bellintani Ribeiro (2008) mostra a aproximação das atividades da tékhne e da epistéme quando revela a intenção de Platão, no diálogo Íon (2011), em distanciar a atividade do poeta (rapsodo) das duas primeiras: "Ora, a explicação é que a atividade do rapsodo, entendida como arte mimética, não se dá por téchne ou epistéme, faculdades tipicamente humanas, mas por força divina (theía dýnamis) e inspiração divina (theía moira). Enquanto o técnico-epistêmico discursa sóbrio, nos limites do discernimento (ém-phron), exercendo certo domínio sobre o seu prágma determinado (a etimologia de epistéme remete à ação de "colocar-se por cima"), o rapsodo fala fora de si (ék-phron), possuído (katechómenos), tomado pelo deus (én-theos), entusiasmado (en-thousiázon)." (RIBEIRO, 2006, p. 133). Negrito nosso. Essa intenção de Platão de afastar a arte do saber enquanto epistéme aparece de forma distinta no dialógo A república (1987), quando esse pensador, associa explicitamente a atividade artística à imitação e à cópia.
} 


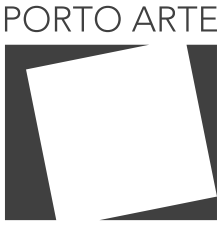

Revista de Artes Visuais

v. 25 ก. 43 Jan/jun 2020 e-ISSN: 2179-8001
Figura 1: Reprodução da pintura O beijo (1961), de Roy Lichtenstein. Fonte: image duplicator.com sobre Warhol e seu trabalho, mantemos nossa posição, apoiados na interpretação de Danto. Como veremos, este artista tem mais a nos revelar em suas obras e afirmações.

Quanto ao segundo elemento da lista, a inclusão e a defesa de Danto em favor de uma ontologia do sensível, explorando o trabalho de Warhol (e obviamente contrariando a posição platônica), coaduna com nossa própria concepção, na medida em que, evidentemente com as particularidades de nossos interesses e objetos de estudo, procuramos preservar esse aspecto da realidade, que fundamenta a empiria e o pragmático na arte, mas também no design.

Por último, torna-se fácil identificar a equivalência do terceiro elemento (dos objetos ordinários com os produtos do design) quando pensamos que Warhol inicia sua criação, por exemplo, com caixas de sabão e latas de sopa e as transforma, ou, na oportuna expressão de Danto (2005), as "transfigura" em obras de arte. Esse é o caminho escolhido nesta investigação para explicitarmos uma das conexões existentes entre design e arte contemporânea.

Danto defende sua posição em diversos momentos e obras. Sua convicção parece, em parte, ser reforçada por uma compreensão diversa daquela de seus colegas críticos de que Warhol não tinha exatamente consciência do que ele mesmo propunha como arte. 0 próprio Danto se questiona, a princípio, sobre a relevância da Pop-Art e de seus seguidores:

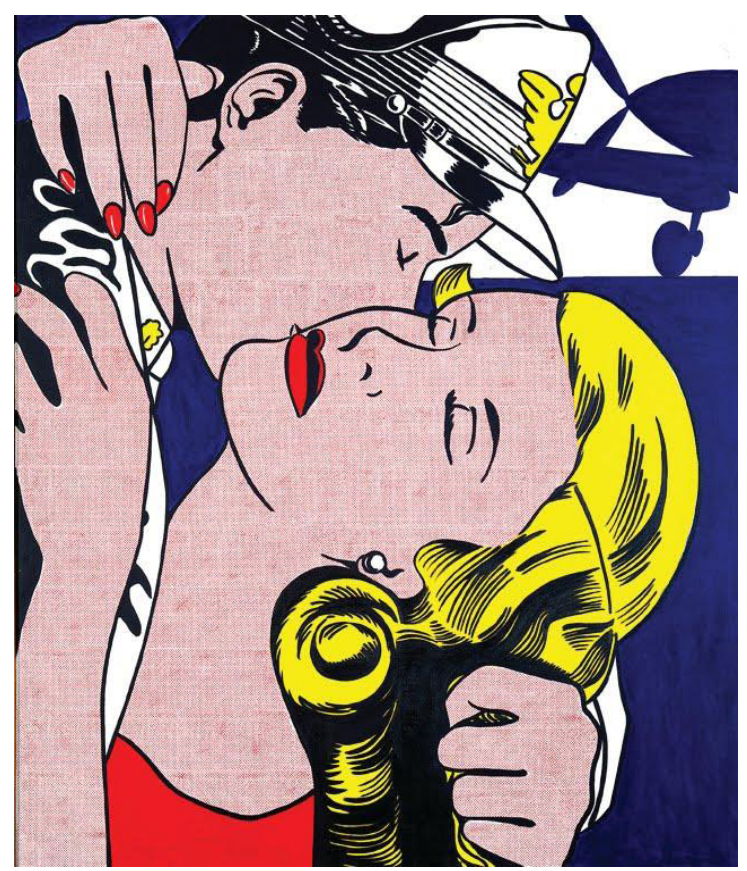




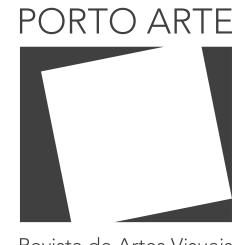

Revista de Artes Visuais
Eu havia me mudado para Nova York após a guerra, motivado por um imenso entusiasmo pela arte da Escola de Nova York, na qual esperava fazer carreira como artista. Eu era veterano de guerra e possuía uma bagagem educacional que decidira aplicar ao estudo da filosofia. Embora tivesse feito algum sucesso como artista, a filosofia acabou se revelando mais interessante para mim. No princípio de 1960, eu era professor da Universidade Colúmbia e estava em gozo de um período sabático na Europa, onde pretendia escrever meu primeiro livro. Foi na Biblioteca Americana de Paris que vi pela primeira vez um trabalho da arte pop: uma reprodução em preto e branco publicada na revista ARTnews. Seu título era O beijo, de Roy Lichtenstein, [Fig. 01] e parecia ter sido recortada da seção de quadrinhos de um jornal americano. Basta dizer que fiquei pasmo. Eu tinha certeza de que aquilo não era arte, mas no decorrer de minha temporada em Paris fui aos poucos elaborando a ideia de que se aquilo era arte, qualquer coisa podia ser arte. Tomei então a decisão de ver tudo o que pudesse da arte pop quando voltasse aos Estados Unidos. (DANTO, 2012, p. 11-12)

Essa perplexidade e incompreensão inicial de Danto, e a sua consequente recusa da Pop-Art, dá lugar a uma visão diversa em relação aos seus colegas críticos da época:

Eu fico freqüentemente impressionado com a ironia de que alguém tão inverossímil como Warhol, que parecia tão pouco dotado de dons e poderes intelectuais no mundo das artes, tão "maneiro", tão ligado na baixa cultura - kitsch! - pudesse ter introduzido intuições filosóficas tão além daqueles seus pares que liam Kant ou que arrotavam existencialismo, citavam Kierkegaard e usavam o vocabulário mais complicado e erudito. Quando eu, em um ensaio que publiquei na época da sua exposição retrospectiva póstuma no Museu de Arte Moderna - MoMA, reivindiquei que ele era o mais próximo de um gênio filosófico que a arte do século vinte havia concebido, fui abordado com pouca aceitação pela grande maioria dos meus amigos, que o considerava num patamar intelectual muito abaixo. (DANTO, 2004, p. 113)

Danto prossegue com sua análise em busca de elementos subjacentes à icônica imagem de Warhol, imagem essa que o próprio artista ajudou a cunhar naquela época, com suas atitudes e afirmações aparentemente banais. E como em outras análises do filósofo, a Brillo Box é seu exemplo preferido: 


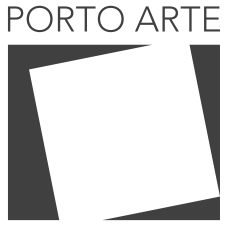

Revista de Artes Visuais

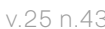

Jan/jun 2020 e-ISSN: 2179-8001

Figura 2: Fotografia da instalação Warhol (1964), Stable Gallery Nova York. Fonte: Revista Ars

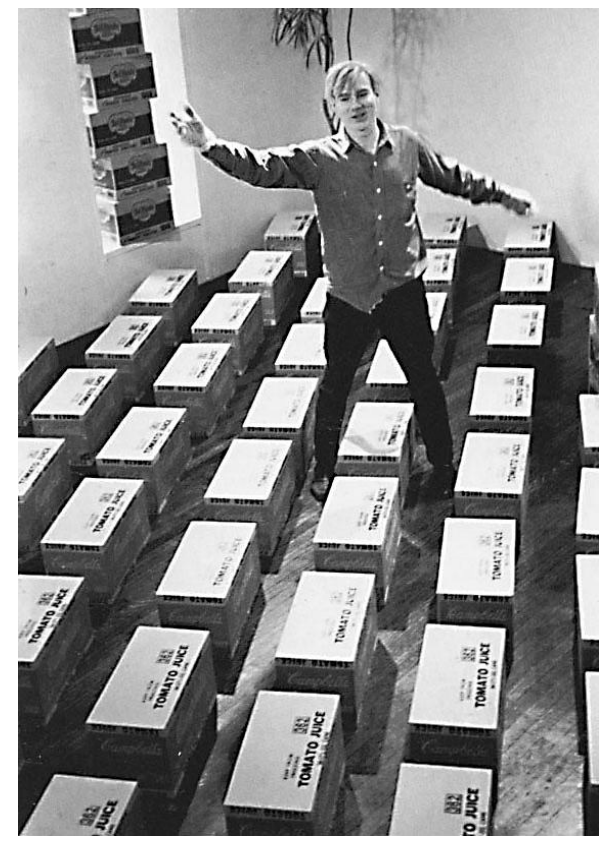

Uma fotografia de Warhol entre suas caixas [fig. 02] parece indistinguível de uma fotografia de um funcionário entre as caixas do supermercado. Com que licença podemos supor que podemos diferenciar uma obra de arte de um objeto meramente utilitário? Um é feito de compensado e o outro de caixa de papelão, mas pode a diferença entre arte e realidade residir numa diferença que "poderia ser de outro modo"? (DANTO, 2004, p. 105-106)

$\mathrm{Na}$ citação anterior, a propósito de expor a forma trivial como a arte de Warhol era divulgada pelo próprio artista, Danto retoma um dos pontos que perpassa sua concepção, ao longo de sua carreira como filósofo da arte. 0 cerne encontra-se na pergunta, que Danto expressa em obras diversas com outras palavras: como diferenciar uma obra de arte de um objeto utilitário? E, obviamente, como filósofo, Danto faz o exercício de sua reflexão conectar-se com a origem ocidental desse problema:

A indagação sobre a definição de arte fazia parte da filosofia desde o tempo de Platão. Mas Andy nos obrigou a repensar a questão de modo inteiramente novo. 0 novo formato da antiga questão era a seguinte: dados dois objetos de aparência exatamente igual, como é possível que um deles seja uma obra de arte e o outro, apenas um objeto comum? (DANTO, 2012, p. 92)

Acrescentando um elemento a mais à já complexa questão da diferenciação, Danto lembra-nos que o projeto gráfico das caixas de sabão Brillo, vendidas em supermercados, foi realizado por James Harvey, que, coincidentemente, também era pintor do Expressionismo Abstrato, estilo ao qual a Pop-Art se opunha frontalmente. E como 


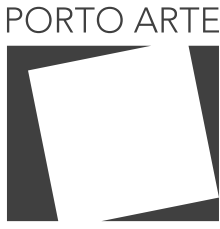

Revista de Artes Visuais v. 25 ก. 43 Jan/jun 2020 e-ISSN: 2179-8001

afirma Danto (2012), Harvey, na condição de autor do "projeto gráfico" da caixa de sabão, não admitiria que esse seu trabalho de "arte comercial" - diríamos de design gráfico - pudesse ser entendido como arte, principalmente sendo ele um expressionista abstrato e obviamente recusando a licenciosidade da Pop-Art. Nas palavras de Danto:

\begin{abstract}
Harvey ficou espantado quando viu, durante a inauguração da exposição das caixas de supermercado de Andy, que a Stable Gallery estava vendendo por centenas de dólares as caixas que ele tinha projetado, enquanto as dele não valiam nada. Mas Harvey, com certeza, não julgava que suas caixas fossem arte. Elas eram reconhecidamente arte comercial, e como tais, excelentes. Deve ser possível explicar por que todo mundo se lembra da caixa de Brillo, mas não, por exemplo, das caixas de suco de maçã da Mott. Não cabe a Warhol o mérito pela genialidade do projeto gráfico da Brillo Box; o mérito é todo de Harvey, mas cabe a Warhol o crédito por transformar em arte o que não passava de um objeto absolutamente corriqueiro da vida cotidiana. Foi ele quem transformou em escultura o que ninguém considerava arte. $\mathrm{E}$ repetiu o feito com caixas de design ainda mais anódinos que a embalagem de Brillo, como a caixa de cereais Kellogg's. Cada uma das oito variedades de caixas era uma escultura, e não apenas a Brillo Box. (DANTO, 2012, p. 92-93)
\end{abstract}

Esta citação é de importância capital por permitir compreender e articular alguns dos elementos e circunstâncias históricas ligadas à criação artística de Warhol e como elas relacionam design e arte. Danto é explícito quanto a identificar que o artista Warhol é o responsável por "transformar" um objeto do uso cotidiano, "caixas de design", em obra de arte escultural, a partir de um projeto gráfico específico de outro artista, que neste caso atua como designer. De nossa parte, nesse emaranhado e prolífico trânsito entre os campos do design e da arte, entendemos essa transformação (ou transfiguração, como Danto aprecia) operada pelo artista como um desvio na significação de um objeto e suas características ontológicas.

Mas o que é essa operação ontológica? Do ponto de vista da aparência, ou do sensível, não é possível distinguir quais são obras de arte, quais são artefatos de design, ou quais se encontram no meio do caminho entre uma esfera da realidade e outra. Assim, apesar das diferenças entre design e arte, no âmbito da experiência sensível, cada vez mais torna-se difícil identificar o que é obra de arte e o que não é. Com essa afirmação não queremos dizer que design e arte podem se tornar campos indistintos. Pelo contrário, o desvio intencional de objetos do design para a arte é o que faculta a objetos indiferenciados em sua forma pertencerem a classes ontológicas distintas, como a do design e a da arte. Conforme afirma Danto: 


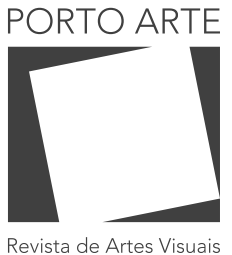

$\vee 25 n .43$ Jan/jun 2020 e-ISSN: 2179-8001
[...] aprender que um objeto é uma obra de arte é saber que ele tem qualidades que faltam ao seu símile não transfigurado e que provocará reações estéticas diferentes. $E$ isso não é institucional, mas ontológico - estamos lidando com ordens de coisas completamente diferentes. (DANTO, 2005, p. 157)

E neste âmbito se encontra a dupla relevância de Warhol:

$1^{\circ} \mathrm{A}$ ocorrência do desvio ontológico, fundamental para a nossa hipótese, se confirma na ação do artista.

$2^{\circ}$ Essa confirmação é explicitada em um objeto em que está contida originalmente a configuração, a estrutura e o propósito do design, e se transforma em obra de arte.

Porém, ainda persiste uma questão que não pode ser desprezada: como ocorre tal desvio? É preciso compreender um pouco do que Warhol pensa e de como seus processos criativos se efetivam na prática artística para, pelo menos, tentar vislumbrar uma resposta.

\section{O desvio da "arte comercial" para a "arte de verdade"}

Warhol corrobora nossos argumentos ao narrar suas memórias de maneira pessoal e desprendida, no livro Popismo (2013), no período em que - enquanto trabalha com "arte comercial"- desperta para o mundo da arte:

\footnotetext{
A pessoa que me formou como artista foi Emile de Antonio quando conheci De, eu era um artista comercial. Nos anos 60, De ficou famoso por seus filmes sobre Nixon e McCarthy, mas nos anos 50 ele havia sido agente de artistas plásticos. Fazia a ligação de artistas com tudo, desde cinemas de bairro até lojas de departamentos e grandes corporações. Mas só trabalhava com amigos: se De não gostasse de você, não se dava ao trabalho.

De foi a primeira pessoa que conheci a ver a arte comercial como arte de verdade e a arte de verdade como arte comercial, e ele fez todo o mundo artístico de Nova York ver as coisas desse jeito também. (WARHOL; HACKETT, 2013, p. 12)
}

Independentemente de Warhol creditar a Emile de Antonio a origem da compreensão de um desvio da "arte comercial" para a "arte de verdade", e vice-versa, o que importa é o próprio desvio em si, que, ao permitir a apropriação de um âmbito da realidade por outro, explicita seu cunho ontológico. Diante disso, é preciso buscar a exata dimensão da questão, indicando como a Pop-Art se distingue e se afasta do Expressionismo Abstrato, fundamentando-se na valorização do mundo sensível e de seus objetos "ordinários". 


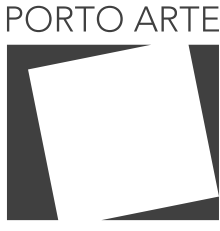

Revista de Artes Visuais

v. 25 ก. 43 Jan/jun 2020

Mas, atentemos, o ordinário e o design, no trabalho de Warhol, não se resumem apenas à constituição da imagem de suas obras. 0 processo de produção também tem sua significação. Por um lado, a caixa e outras obras de arte criadas por ele e montadas em série em seu ateliê em uma linha de produção - não sem razão nomeado Factory (como conta um de seus assistentes, Gerard Malanga ${ }^{2}$ ) - mimetizam o processo da mecanização de uma fábrica. Por outro, esse processo não é simplesmente cópia de uma fábrica, pois é executado manualmente por ele e seus assistentes, com o cuidado e a atenção que suas obras exigem. Conforme Danto:

É como se a realidade não fosse mecânica o suficiente para se acomodar a imaginação de Warhol. É importante notar ainda que o trabalho era tão central em sua concepção da arte que a ideia de usar como arte algo que não resultasse do trabalho não teria interesse nenhum para ele. (DANTO, 2012, p. 77-78)

Tal imersão no cotidiano da vida mescla de um lado elementos de projeto e de produção de objetos utilitários, de consumo, e suas embalagens, como ocorre no design, e de outro a criação no fazer artístico. Como resultado, um dos seus sentidos é o escultural:

Quando pensamos em escultura, lembramos de Michelangelo, Canova, Rodin, Brancusi ou Noguchi, que criaram objetos únicos de beleza e significado. Antes de Warhol, jamais ocorreria a alguém criar, como escultura, uma coisa semelhante a uma caixa de papelão para transporte de mercadorias de consumo. Warhol não só fez exatamente isso como usou um processo que, de certo modo, parodiava a produção em massa. (DANTO, 2012, p. 76)

Se retomarmos a fotografia de Warhol junto com as pilhas de caixas (conforme a Fig. 02), veremos como a ambiguidade do papel do artista combina com essa "paródia da produção". E a decisão de investir um objeto de novos significados, transfigurando-o de artefato ou utensílio em obra de arte, recai assim sobre a responsabilidade do artista. A visão de Danto se harmoniza com a ideia de um desvio ontológico em que a arte conduz objetos do design para a sua esfera, ao alterar seus significados.

Um exemplo adicional no gênero da pintura, mas com as mesmas características da caixa de sabão, é o das latas de sopa Campbell, que possui, segundo Danto, rela-

\footnotetext{
2- Conforme Danto: "Malanga é nossa fonte principal sobre a confecção dessas caixas e sobre a ideia de Andy de organizar a Factory segundo linhas industriais, um paradoxo porque as pessoas que participavam da Factory eram tudo menos robôs. Andy estava fascinado pelas prateleiras dos supermercados e pelo efeito repetitivo, maquinal, que criavam [] Ele queria reproduzir esse efeito, mas logo descobriu que a superfície de papelão era impraticável. Como o efeito em questão é geralmente obtido pelo empilhamento de caixas de papelão em armazéns e depósitos, é difícil entender o que havia de errado com o papelão, que Warhol podia ter usado com muito menos esforço, simplesmente comprando as embalagens dos fabricantes e tratando-as como ready-mades." (DANTO, 2012, p. 77-78)
} 


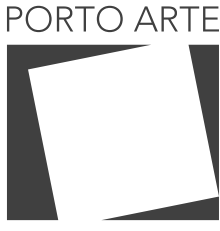

Revista de Artes Visuais v. 25 ก. 43 Jan/jun 2020 e-ISSN: 2179-8001 tos diferentes acerca de sua origem. Entre aquelas narrativas que circulavam em Nova York, a da preferência de Danto é a de que Warhol solicitou uma ideia à designer de interiores Muriel Latow:

\begin{abstract}
Warhol disse a Latow que precisava de uma ideia "de grande impacto, diferente de Lichtenstein e Rosenquist, algo bem pessoal, que não pareça que estou fazendo exatamente o que eles fazem". Latow respondeu-Ihe que ele devia pintar alguma coisa que "todo mundo vê todos os dias, que todo mundo reconhece como uma lata de sopa". A própria maneira como Warhol formulou a pergunta já eliminava muitas possibilidades. Ele não estava interessado em pintar uma abstração bonitinha e agradável, ou Manhattan ao luar, ou uma mulher bonita lendo uma carta perto da janela. Tinha de ser algo ligado à cultura comum que ainda não tivesse sido trabalhado por ninguém. Algo que as pessoas comentassem mesmo sem ter visto.
\end{abstract} (DANTO, 2012, p. 58)

Esse tipo de comportamento em relação às ideias dos outros, descrito por Danto na citação anterior, é confirmado por Warhol, em seu livro Popismo:

Nunca tive a menor vergonha de perguntar a alguém, literalmente: "O que devo pintar?", porque o Pop vem de fora, e que diferença existe entre pedir idéias a alguém ou procurar numa revista? Henry [Henry Geldzahler, curador do Metropolitan Museum of Art] entendeu isso, mas algumas pessoas o desprezam se você pede conselho a elas, não querem saber nada sobre como você trabaIha, querem que você conserve a sua mística para elas poderem te adorar sem ficarem envergonhadas com as especificidades. (WARHOL; HACKET, 2013, p. 27)

Ao lado dessa atitude que pode, como o próprio Warhol diz, incitar críticas, Danto reforça aquela característica já apresentada do trabalho de Warhol que desloca a atenção do artista de uma ideia originária, ponto de partida para uma obra de arte, indo ao encontro das escolhas envolvendo os processos de criação e diferentes gêneros de arte, como as instalações, compreendendo-os como centrais na produção artística. Se Warhol opta por não necessariamente ser o autor da ideia, ele não simplesmente a executa como um operário em uma linha de produção:

Uma coisa é dizer ao artista que ele devia pintar latas de sopa, outra é decidir como pintá-las. A decisão de Warhol envolveu mais que a mera pintura de uma lata de sopa. Ele construiu um painel com trinta 


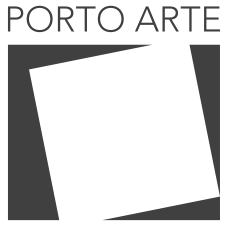

Revista de Artes Visuais

v. 25 ก. 43 Jan/jun 2020 e-ISSN: 2179-8001 e duas telas $(50,8 \times 40,6 \mathrm{~cm}$ cada), organizadas em quatro fileiras de oito, cada tela representando uma das variedades das sopas Campbell produzidas naquela época - como uma instalação de retratos de pessoas notáveis. (DANTO, 2012, p. 58-59)

Considerando a reconstituição de alguns elementos das narrativas sobre o processo de criação de Warhol, compreendemos como Danto não somente defende, mas também destaca a relevância desse artista na história da arte:

Em termos ainda mais incisivos, pode-se dizer que seria impossível que as caixas de Warhol fossem arte muito antes de 1964. 0 grande historiador da arte Heinrich Wolfflin disse que nem tudo é possível em todas as épocas. A história da arte sempre está aberta a novas possibilidades, mas não teria aberto a possibilidade de um objeto como uma caixa de Brillo ser arte, digamos, em 1874, quando a pintura impressionista era a vanguarda. (DANTO, 2012, p. 91)

A defesa que Danto faz da relevância da Pop-Art e de Andy Warhol, como ele mesmo afirma, encontra resistência em outros críticos americanos. E Danto também nos lembra de mais uma interpretação diametralmente oposta, vinda da crítica europeia, implicando a Pop-Art com uma condenação irônica à cultura e aos valores americanos:

Estivesse ou não correta a interpretação dos europeus de que a arte pop continha uma crítica da cultura dos Estados Unidos, a verdade é que eles pelo menos perceberam que havia algo mais na nova arte do que nossos olhos americanos podiam ver. De sua parte, Andy ansiava por apresentar-se aos europeus como tudo menos um artista fútil. (DANTO, 2012, p. 9-10)

Contrabalançando essas posições apresentadas por Danto, a filósofa Virginia Figueiredo oferece sua contribuição, contextualizando a posição deste autor:

Não tenho a menor idéia se ele [Danto] concordaria com este epíteto, mas, no meu modo de ver, ele é "O filósofo da Pop-Art", sintetizando-se aqui grosseiramente sob o nome "Pop-Art" a produção norte-americana de arte a partir do final dos anos 1950 e início dos anos 1960), da qual, talvez, ele mais do que qualquer outro, tentou extrair o aspecto crítico, diminuindo a margem ambivalente, a do elo inegável, para muitos outros críticos, motivo de uma condenação irreparável com o mercado e com a indústria cultural. Sabe-se o quão pequena 


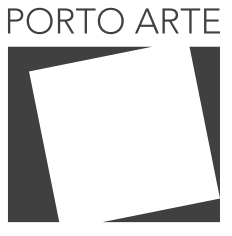

Revista de Artes Visuais

v. 25 ก. 43

Jan/jun 2020 e-ISSN: 2179-8001
Figura 3: Reprodução do quadro 200 notas de um dolar (1962), de Andy warhol. Fonte: sothebys.com foi a diferença que a maioria dos críticos viu entre o movimento da Pop-Art e a propaganda direta. ${ }^{16}$ Ainda no meu modo de ver, Danto tenta pôr a produção da arte contemporânea dos norte-americanos em sintonia com os movimentos da vanguarda européia do início do século XX. Se não em "sintonia", talvez em busca de um "lastro" ou de uma legitimação histórica, visando à conquista de um lugar na história mundial (internacional) daquela produção. Tratava-se, a meu ver, portanto, de um possível processo de "internacionalização" da arte norte-americana, da chamada mudança de referencial, de Paris para Nova York. Nada mais "político", portanto. Não é à toa que ele põe em diálogo, de modo recorrente, artistas como Andy Warhol e o francês Marcel Duchamp (1887-1968). (FIGUEIREDO, 2005, p. 449-450) 16 Cf. MCCARTHY, David. Arte Pop. Trad. Otacílio Nunes. São Paulo: Cosac \& Naify, 2002. p. 35. [nota em pé de página da autora]

A conexão de Warhol com Duchamp, que Figueiredo nos lembra, será analisada a seguir. Mas as palavras do próprio Warhol não negam a importância que o mercado de consumo tem para os norte-americanos e para ele. 0 entendimento que Warhol tem acerca do consumismo, do qual ele não vê problema em assumir, se revela em obras como a da Fig. 03, e em seu livro A filosofia de Andy Warhol: de A a B e de volta a A:

Comprar é muito mais americano que pensar e eu sou absolutamente americano. Na Europa e no Oriente, as pessoas gostam de comerciar - comprar e vender e vender e comprar; são basicamente mercadoras. Americanos não estão interessados em vender - na verdade, eles preferem jogar fora a vender. 0 que eles realmente pensam é em comprar - pessoas, dinheiro, países. (WARHOL, 2010, p. 255)

\begin{tabular}{|c|c|c|c|c|c|c|c|c|}
\hline & & & & & & & & \\
\hline$M=d B=25 A$ & & & & [1 & & & & \\
\hline 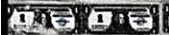 & Eह & & B) & वस्त्र & & & $\overline{M E}$ & \\
\hline 18: $1: \Rightarrow$ & कह & (I) & तथह & प7ar) & 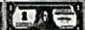 & IxA- & & \\
\hline 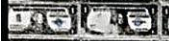 & & & $2 \sqrt{3 x}$ & (1983) & d & $2: 0$ & 람 & \\
\hline (1) $10 \mathrm{y}$ & BA? & (I:B & (7: & 18: & (1) & (20) & $\sqrt{3} \times 15$ & (3:2 \\
\hline 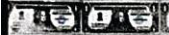 & $28 \mathrm{~s}$ & $(1,2)$ & inf & (3:E) & 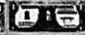 & $2 a=$ & घ: & \\
\hline 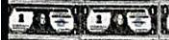 & तaE & IIf & (5) & (192] & $\square: 0$ & (1DE) & (12B & $\sqrt{172}$ \\
\hline 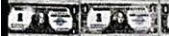 & (1) & Igry & तथह & $\square \Rightarrow$ & DIF & $4 x=$ & (I) & $\sqrt{2}$ \\
\hline 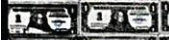 & IAE & $\int$ & I9E & 310 & 21170 & (2): & $\angle 7 \theta$ & $\sqrt{2 x}$ \\
\hline 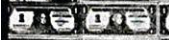 & पत्ह & DaE & (2):룜 & 19E & 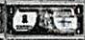 & FE & (39=0 & (19) \\
\hline 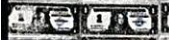 & IIF & InE & IDE & तga & IMF & Ix) & (3) & 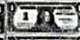 \\
\hline हचग $10 \%$ & $7 \times x_{0}^{0}$ & उत्य & nge & (3:E & $\sqrt{100}$ & IDE & (10B & 12 \\
\hline (2) (120) & पूर랄 & lane & inge & $2 \pi$ & 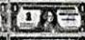 & $\sqrt{2 x}$ & जलㄹ & 12 \\
\hline Ba? & & IEI & $x \in$ & & & & प9B & 27 \\
\hline & & & & & & & & \\
\hline
\end{tabular}




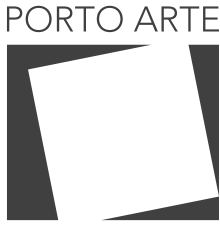

Revista de Artes Visuais v. 25 ก. 43 Jan/jun 2020 e-ISSN: 2179-8001

Se a associação da Pop-Art com o mercado e a indústria cultural (e Warhol está longe de negar tal vínculo) pode ser entendida como negativa por parte da crítica artística, por outro lado, ela também é indício de que a arte contemporânea pode assumir não querer prescindir desses vínculos. Esse é um dos pontos em comum que a arte tem com diversos outros campos, inclusive a propaganda e o design.

\section{Duchamp: precursor ou mensageiro?}

Mas Danto também não ignora a importância histórica de Duchamp. Ele tem plena consciência de que "a precedência de Marcel Duchamp projeta uma certa sombra sobre todos os subseqüentes esforços de delimitar as fronteiras da arte." (DANTO, 2004, p. 107). Assim, ele argumenta sobre a clivagem distinta da proposta de Warhol para a arte em relação ao que aparentemente já havia sido realizado em 1917, por Duchamp, com A fonte.

De forma radical, Danto afirma que (em princípio) a indistinção entre obras de arte e coisas reais decreta o que ele nomeia de "O fim da Arte" (DANTO, 2012, p. 95), ou, em outras palavras, o fim de uma história acerca dos movimentos artísticos. Não é nosso propósito analisar a concepção de Danto acerca do fim $^{3}$ da arte, tema que implica diversos conceitos fora do escopo deste artigo. No entanto, a expressão fim da arte por si só denota o grau de relevância que este filósofo atribui a Warhol, não somente dentro do fenômeno da Pop-Art, mas em relação à Duchamp e também na história da arte como um todo:

\footnotetext{
Alguns críticos me perguntam por que acho que Warhol pôs fim à história da arte da maneira como a entendíamos antes - por que não Duchamp com seus ready-mades? Ora, a verdade é que Andy fazia suas caixas, enquanto Duchamp, de maneira geral, não podia fazer seus ready-mades. Só que nem todo objeto pode ser um ready-made, já que Duchamp os restringia a objetos indistinguíveis do ponto de vista estético. Mas por que fazer essa restrição, a não ser que se tenha uma persistente aversão à arte retiniana? (DANTO, 2012, p. 95)
}

Na concepção de Danto, o que subjaz à posição duchampiana é que ele criticava o entendimento da estética clássica que valorizava o prazer visual, ou o chamado sentido "retiniano": “"O deleite estético é o inimigo a ser derrotado" - diz Duchamp com relação a esse gênero de trabalho, pois os readymades, segundo ele, foram escolhidos precisamente pela sua falta de interesse visual." (DANTO, 2004, p. 107).

Além da aversão à arte retiniana de Duchamp, que não procura mediação, e mostra-se como uma das diferenças entre o Dadaísmo e a Pop-Art, Danto acrescen-

\footnotetext{
3- Danto não é o primeiro teórico a propor e tratar do tema do fim da arte. Ele é precedido por filósofos como Hegel, Marx, Nietzsche, Lukács, Benjamin, Heidegger, Horkheimer e Adorno. Para uma análise detalhada do tema, ver Rodrigo Duarte (2006)
} 


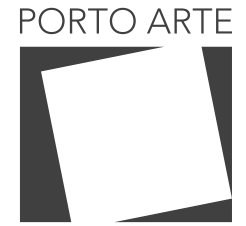

Revista de Artes Visuais

v. 25 n. 43 Jan/jun 2020 e-ISSN: 2179-8001
Figura 4: Fotografias de A fonte (1917), de Marcel Duchamp (esquerda) e da Brillo Box (1964) de Andy Warhol (direita). Fontes: tate.org e moma.org ta um comentário aos seus argumentos, no tom leve que caracteriza seu livro Andy Warhol, mas que não deixa de nos fazer pensar sobre o sentido da vida cotidiana que Warhol e Duchamp capturam, cada um a seu modo, através dos objetos do mundo sensível (fig. 04):

Uma coisa deve ser dita a respeito das Brillo Boxes: elas são muito bonitas. Minha esposa e eu temos uma há anos, e ainda nos maravilhamos com sua beleza. Por que teríamos de conviver com objetos esteticamente desinteressantes em vez de coisas tão bonitas quanto a Brillo Box? (DANTO, 2012, p. 95)
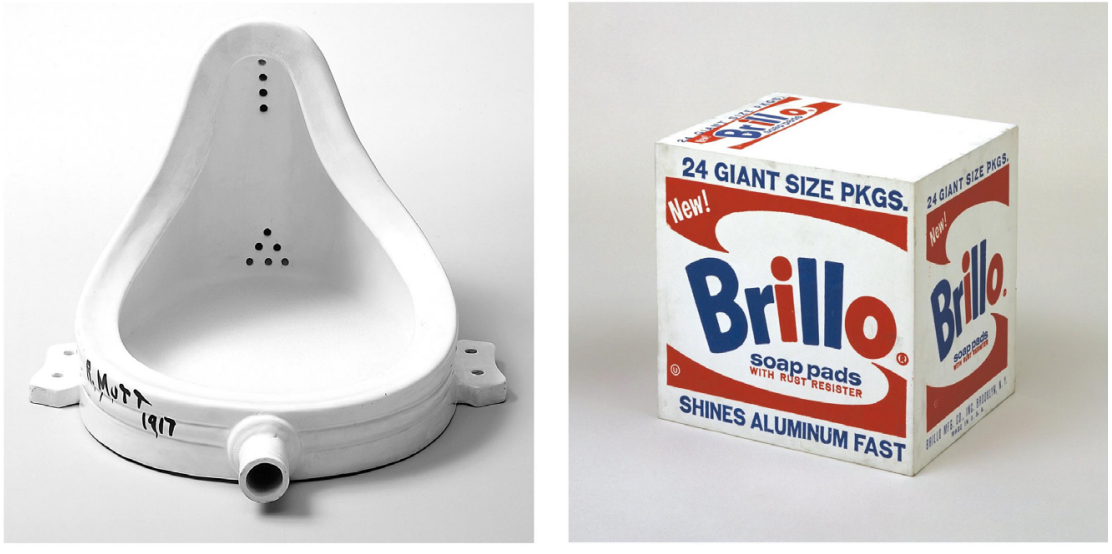

Enquanto Duchamp pode, entre suas motivações, usar "[...] o banal como um tipo de bomba contra o conceito fortificado de arte [...]" (DANTO, 2004, p. 108), e essa é uma atitude não só de Duchamp, mas do movimento ao qual ele pertencia, o Dadaísmo, Warhol, de modo distinto, compreende o banal e o corriqueiro como algo que pode e deve ser incorporado à arte. Além disso, segundo Danto, Warhol, com sua proposta, coloca uma pergunta de caráter filosófico - ultrapassando Duchamp, que não perguntou "Por que todos os outros urinóis não eram obras de arte?"-, "Por que a Brillo Box era uma obra de arte enquanto as caixas de Brillo comuns eram meras caixas de Brillo?" (DANTO, 2004, p. 108).

Outra interpretação acerca da concepção e do papel de Duchamp, que acrescenta mais elementos para a questão, é a do filósofo Thierry de Duve. Em uma palestra que posteriormente foi publicada na forma de artigo, de Duve, primeiramente, considera que somente na década de 1960 a "mensagem" de Duchamp foi assimilada, o que em certo sentido destaca o papel visionário deste artista: 


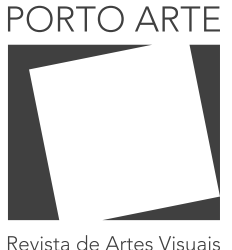

v. 25 . 43 Jan/jun 2020 e-ISSN: 2179-8001
0 mundo da arte não acusou verdadeiramente a recepção da mensagem de Duchamp antes dos anos 60, quando, nos rastros do neodadá (pop arte, aliás), da minimal art e da arte conceitual, começou a definir-se de modo mais ou menos consciente como pós-duchampiano. (DE DUVE, 2010, p. 192)

No entanto, se Duchamp foi o mensageiro, para de Duve, isso não significa que ele tenha sido responsável pela mensagem:

\begin{abstract}
Alguns até atribuem o feito unicamente a Marcel Duchamp, sempre ele: ao inventar o ready-made, Duchamp teria criado um novo gênero artístico e um novo personagem, o artista simplesmente. Essa opinião comete o erro de interpretação clássico ao fazer do mensageiro o responsável pela mensagem que traz. Minha palestra de hoje tem o objetivo de corrigir esse erro de interpretação. A arte em geral não substitui os meios tradicionais, como a pintura e a escultura; não se vem juntar aos gêneros tradicionais, como a paisagem ou o nu; não é um novo estilo que se possa reconhecer por algum traço comum, como os "ismos" abundantes no século 20. A pintura e a escultura, a paisagem e o nu, e todos os "ismos" do século 20 fazem parte, ao contrário, da arte em geral, já que ela nada exclui e inclui, além disso, as práticas recentes - a instalação, a arte conceitual ou a videoarte, assim como outras que ainda não têm nome. De fato, o teor da expressão é o seguinte: fazer arte com tudo e com qualquer coisa é hoje tecnicamente possível e institucionalmente legítimo [...] (DE DUVE, 2010, p. 182-183)
\end{abstract}

Em outro trecho, de Duve é mais explícito em sua afirmação: "Duchamp é apenas o mensageiro. Seja para o incensar ou maldizer, é um erro de interpretação atribuir ao mensageiro a responsabilidade pelo conteúdo da mensagem." (DE DUVE, 2010, p. 186).

\section{0 que a arte inclui}

Quer concordemos ou não com de Duve acerca do papel e consciência do mensageiro, o que importa destacar no interior da interpretação deduviana é o entendimento desse autor de que a arte em geral "nada exclui e inclui". Tal compreensão se encontra exposta no artigo Subjetividade e objetividade: antinomia kantiana do gosto na arte e no design, onde apresentamos as discordâncias de Thierry de Duve com as posições antagônicas do crítico de arte Clement Greenberg e do artista e ensaísta Joseph Kosuth (SILVA; DE MORAES, 2019). Tal antagonismo se levado ao extremo conduz a uma antinomia: ou procurar uma continuidade na história da arte, entender o readymade com uma fraude e rejeitar a antiarte e movimentos do Dadaísmo em diante, ou entender a 


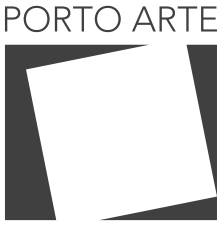

Revista de Artes Visuais

$\vee 25 n .43$

Jan/jun 2020 e-ISSN: 2179-8001

arte como conceitual, depois do readymade, e anular toda a arte anterior a Duchamp. Como exposto no artigo, de Duve, de modo consistente, recusa as duas posições radicais e propõe uma solução mediadora e inclusiva.

Danto, de modo correlato, também é partidário dessa inclusão que a arte propõe. Ao final do livro, A transfiguração do lugar comum, ele, a propósito da admissão da Brillo Box no mundo da arte, afirma: "Sua reivindicação [a da Brillo Box] parece ser ao mesmo tempo revolucionária e risível: ela não deseja subverter a sociedade das obras de arte, mas ser admitida nela, ocupando o mesmo lugar dos objetos sublimes." (DANTO, 2005, p. 296).

Atentos a esse espírito de mediação e inclusão que atravessa as concepções de Arthur Danto, e de Thierry de Duve, na nossa perspectiva, tanto Duchamp quanto Warhol, promovem um desvio ontológico com suas concepções e suas obras de arte, independentemente da posição que se assume em relação a quem tem mais relevância, se Duchamp ou Warhol.

\section{Considerações finais}

É preciso admitir que, mesmo com algumas dessas questões já pacificadas na história e teoria da arte, esta investigação apresenta mais perguntas do que respostas definitivas, e essa é uma característica de reflexões filosóficas. Assim, não é possível pensarmos em uma conclusão no sentido estrito do termo. 0 mais apropriado é dispor algumas considerações acerca daquilo que não se pode compreender com o uso exclusivo de uma razão quantificadora. Neste sentido, a trajetória que seguimos de algum modo contribui para o entendimento de que ao ampliarmos nossa compreensão da complexidade da cultura contemporânea, também crescem nossas incertezas. Essa característica não é uma prerrogativa das áreas humanas, sociais e das artes. Outros campos de pesquisa enfrentam a ampliação do desconhecido enquanto expandem o conhecimento de seus objetos de estudo. No entanto, não entendemos essas indeterminações como problemas: é fundamental fomentar dúvidas para mover adiante campos como a arte e o design. É nesse sentido que a pergunta de Danto, que apresentamos no início deste escrito ainda permanece como um desafio: como diferenciar uma obra de arte de um objeto utilitário? Ao criticar a teoria institucional da arte esse autor mostra como essa questão está longe de ter uma resposta simples:

Creio que subsistem perplexidades análogas na análoga teoria da arte segundo a qual um objeto material (ou artefato) é uma obra de arte quando o arcabouço institucional do mundo da arte assim o considera. A teoria institucional da arte não explica, embora permita justificar, por que a Fonte de Duchamp passou de mera coisa a obra de arte, por que aquele urinol específico mereceu tão impressionante promoção, enquanto outros urinóis obviamente idênticos a ele continuaram relegados a uma categoria ontologi- 


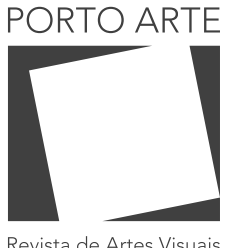

v. 25 n. 43 Jan/jun 2020 e-ISSN: 2179-8001

camente degradada. A teoria deixa ainda em aberto o problema de outros objetos indiscerníveis, dos quais um é uma obra de arte e o outro não. (DANTO, 2005, p. 39)

A filósofa Virginia Figueiredo corrobora as palavras de Arthur Danto e sintetiza esse desafio que pertence à contemporaneidade, unindo seu pensamento ao de Thierry de Duve:

\footnotetext{
[...] a meu ver, todo e qualquer critério objetivo ou conceito prévio, seja ele de belo, de feio, ou de sublime, está fadado ao fracasso na sua tentativa de apreensão filosófica da produção recente da arte. Num ambiente em que "tudo pode ser arte", a necessidade de uma reflexão singular, caso a caso, só se agrava. Mesmo sem, ou exatamente porque não dispõe de qualquer critério ou conceito estabelecido a priori (daí decorre uma das grandes dificuldades das condições contemporâneas da experiência estética), o espectador não pode permanecer passivo, acatando tudo o que lhe colocam diante dos olhos, como se fosse arte. Mais do que nunca, o espectador está "obrigado" ao exercício da crítica, mais do que nunca, ele tem de se perguntar, como de Duve nos indicou: “isto é arte?” (FIGUEIREDO, 2008, p. 37)
}

Apesar das diferenças conceituais entre os autores das análises, acreditamos que todos os envolvidos nas reflexões partilham da compreensão de que, na atualidade, a ampliação dos domínios da arte leva cada um de nós a assumir a responsabilidade de nossas escolhas, quando conscientemente despertamos para a relevância do que nos comove, no sentido originário de sermos movidos com (cum-mouěo) a arte. Saber que artistas como Warhol e Duchamp acrescentam mais questões polêmicas para as nossas escolhas, incorporando objetos do cotidiano em suas obras, torna a experiência da fruição da arte muito mais atraente e instigante. De modo correlato, acreditamos que essa capacidade de problematizar, que é inerente à arte e à filosofia, também pertence ao design e contribui para uma compreensão mais apurada do que sejam os seus propósitos, enquanto um campo aberto a novas e ricas possibilidades.

$O$ desvio de elementos do design para a arte descreve somente uma parte de uma dinâmica ontológica mais ampla. 0 caminho inverso, em que conceitos da arte são intencionalmente apropriados pelo design, completa um movimento circular de ida e volta que manifesta parte das complexas relações entre esses dois campos. Mas esse é um tema para outra investigação. 


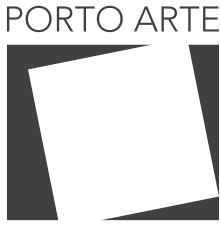

Revista de Artes Visuais

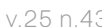

Jan/jun 2020 e-ISSN: 2179-8001

\section{REFERÊNCIAS}

ARISTÓTELES. A poética. Tradução, comentários e índices analítico e onomástico Eudoro de Souza. Coleção Os Pensadores, v. 2. São Paulo: Nova Cultural, 1987.

DANTO, Arthur C. O filósofo como Andy Warhol. Tradução Nara Beatriz Milioli Tudida. ARS, v.2, n. 4, São Paulo, 2004. Disponível em: < http://www.revistas.usp.br/ars/ article/view/2935/3625 >. Acesso em: 01 ago. 2017.

DANTO, Arthur C. A transfiguração do lugar-comum: uma filosofia da arte. Tradução Vera Pereira. São Paulo: Cosac \& Naify, 2005.

DANTO, Arthur C. Andy Warhol: Arthur C. Danto. Tradução Vera Pereira. São Paulo: Cosac \& Naify, 2012.

DE DUVE, Thierry. Kant after Duchamp. Cambridge, MA: MIT Press, 1996.

DE DUVE, Thierry. O que fazer da vanguarda? Ou o que resta do século 19 na arte do século 20? Arte \& Ensaios, n. 20, p. 181 - 193. Rio de Janeiro: Mestrado em História da Arte/Escola de Belas Artes, UFRJ, 2010. Disponível em: <https:/ www.ppgav.eba.ufrj.br/wp-content/uploads/2012/01/ae20_Thierry_Duve. pdf> Acesso em: 9 jun. 2019.

DUARTE. Rodrigo. $\mathrm{O}$ tema do fim da arte na estética contemporânea In: Arte no pensamento. Org. Fernando Mendes Pessoa. Vila Velha: Museu Vale do Rio Doce, 2006. p. $376-414$.

FIGUEIREDO, Virginia. Isto é um cachimbo. Kriterion: Revista de filosofia v. 46, n.112, p. 442 - 457 , dez. 2005. Disponivel em: < http://www.scielo.br/pdf/kr/v46n112/v46n112a24.pdf > Acesso em: 07 ago. 2019.

FIGUEIREDO, Virginia. Kant e a arte contemporânea. Especiaria - Cadernos de ciências humanas. v. 11, n.19, p. 25 - 43, jan./jun. 2008. Disponivel em: <http://periodicos. uesc.br/index.php/especiaria/article/view/720/679> Acesso em: 09 jun. 2019.

PLATÃO. A república. Introdução, tradução e notas Maria Helena da Rocha Pereira. $5^{a}$ edição. Lisboa: Fundação Calouste Gulbenkian, 1987.

PLATÃO. Íon. Introdução, tradução e notas Cláudio Oliveira. Belo Horizonte: Autêntica, 2011.

RIBEIRO, Luís Felipe Bellintani. Arte no pensamento de Platão. In: Arte no pensamento. Org. Fernando Mendes Pessoa. Vila Velha: Museu Vale do Rio Doce, 2006. p. $102-135$.

SILVA, S.L.; DE MORAES, D. Subjetividade e objetividade: antinomia kantiana do gosto na arte e no design. Estudos em Design. Rio de Janeiro: v.27, n. 3, p. 62 - 78, 2019. Disponivel em: <https://doi.org/10.35522/eed.v27i3.773>

WARHOL, Andy. A filosofia de Andy Warhol: de a a b e de volta a a. Tradução José Rubens Siqueira. Rio de Janeiro: Cobogó, 2010.

WARHOL, Andy; HACKETT Pat. Popismo: os anos 60 segundo Warhol. Tradução José Rubens Siqueira. Rio de Janeiro: Cobogó, 2013. 


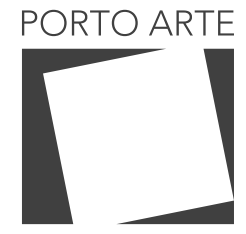

Revista de Artes Visuais

V.25 n. 43

Jan/jun 2020 e-ISSN: 2179-8001

Texto recebido em: 10/03/2019

Texto aceito em: $25 / 06 / 2020$ Texto publicado em: 30/06/2020

\section{Sérgio Luciano da Silva}

Graduação (1991) e Especialização (2006) em Filosofia pela UFMG. Mestrado (2011) e Doutorado (2019) em Design pela UEMG. Pós-doutorado em andamento pela UEMG (2020-). Pesquisador do grupo do CNPq Design e Representações Sociais (2011). Sócio da Adaequatio Estúdio de Criação Ltda (2000-2016), onde atuou como diretor de arte, arte-finalista e produtor gráfico em expografia, sinalização e editorial. Professor da Escola de Design da UEMG (2013-2017) em Design Editorial, Materiais e Processos de Produção, Fatores Filosóficos e Teoria e Prática Caligráfica. Orientador de projetos de conclusão de curso no mesmo período. Como desdobramento de seus estudos e prática profissional, suas investigações avançam em duas linhas de pesquisa. TEORIA E CRÍTICA DO DESIGN: apropria-se de conceitos da Filosofia, em especial da Ontologia, Teoria do Conhecimento e Estética, reelaborados na tese de doutorado para a fundamentação do Design. ESTUDOS DA ESCRITA: baseia-se na metodologia da sua dissertação de mestrado e do livro Faces e Fontes Multiescrita, unindo as escritas grega, latina, cirílica e hebraica à prática da caligrafia medieval e renascentista, direcionando-as ao design tipográfico multiescrita. 